\title{
O Ensino de Sociologia no Uruguai: uma análise a partir das narrativas dos professores
}

Amurabi Oliveira

\section{Resumo}

Este trabalho examina o ensino de Sociologia no Uruguai considerando tanto as peculiaridades em termos de sistema educativo, como também, e principalmente, as avaliações realizadas por professores de Sociologia. Metodologicamente o trabalho baseia-se em entrevistas semiestruturadas realizadas em Montevidéu, com ênfase nas trajetórias dos agentes e em suas disposições sociais incorporadas. Observa-se que os professores uruguaios consolidam uma identidade docente ainda em sua formação inicial; porém, há um evidente recorte geracional entre aqueles que realizaram a formação antes e depois de 2008. Também foi encontrada como característica uma forte posição "antimanualista" dos professores de sociologia uruguaios, reforçada pela tendência de combinarem diferentes metodologias de ensino em suas práticas.

Palavras-chave: Ensino de Sociologia. Professores de Sociologia. Sociologia na América Latina. Sociologia no Uruguai.

\section{Introdução}

Em que pese o incremento da produção acadêmica nos últimos anos (CAREGNATO; CORDEIRO, 2014; BODART; CIGALES, 2017; HANDFAS, 2017), ainda são poucos trabalhos que se propóem a realizar uma análise comparativa entre a realidade do ensino de sociologia em distintos contextos nacionais (Oliveira, 2014), algumas exceçóes são os

Doutor em Sociologia pela Universidade Federal de Pernambuco (UFPE), Professor da Universidade Federal de Santa Catarina (UFSC).Pesquisador do CNPq.E-mail: amurabi_cs@hotmail.com

\section{$(\infty))$ EY}

Direito autoral e licença de uso: Este artigo está licenciado sob uma Licença Creative Commons. Com essa licença você pode compartilhar, adaptar, para qualquer fim, desde que atribua a autoria da obra, forneça um link para a licença, e indicar se foram feitas alterações. 
trabalhos de Leithauser e Weber (2010) e Maçaira (2017), autores que, a partir de enfoques diferentes, realizam uma primeira aproximação comparativa entre as realidades do Brasil com países como Alemanha e França. Visando a contribuir para esta discussão, proponho-me neste trabalho realizar uma análise acerca do ensino de sociologia no Uruguai, partindo da avaliação dos professores que atuam na educação básica, trazendo com isso alguns elementos comparativos com o caso brasileiro.

Uma análise comparativa a rigor demandaria um exame do desenvolvimento sócio-histórico da sociologia nos diferentes contextos nacionais, assim como dos distintos arranjos existentes com relação ao sistema educativo nos dois países, especialmente com relação ao Ensino Médio (educação secundária, no caso uruguaio). Todavia, isso não implica afirmar que náo haja a possibilidade de indicar pontos em comuns em termos de trajetórias da disciplina nos dois países, condicionadas pela conjuntura sociopolítica de cada país.

As distintas histórias que as ciências sociais são amiúde mutuamente desconhecidas entre os países da América Latina, especialmente quando se considera a história da sociologia como componente curricular escolar. Foge do foco e do escopo deste trabalho realizar uma retomada dessa história do ensino de sociologia no Brasil²; todavia, é interessante ressaltar alguns pontos substancialmente diversos que encontramos nos dois países aqui analisados.

Se no caso brasileiro a sociologia permanece ausente no período da ditadura militar ${ }^{3}$, o que contrastou com o incremento no número de cursos de graduação em Ciências Sociais (LIEDKE FILHO, 2005), por outro lado, no Uruguai a sociologia é implementada nos currículos escolares justamente no período ditatorial, havendo de forma concomitante um

2 Para um maior aprofundamento por parte do leitor desse debate vide os trabalhos de: Silva. Alves Neto $e$ Vicente, 2010; Moraes, 2011; Meucci, 2015; Oliveira, 2013.

3 Interessante perceber que diferentemente do que apontam alguns trabalhos na área, a extinção do ensino de sociologia no currículo escolar não foi provado pela ditadura militar iniciada em 1964, uma vez que sua exclusão se deu ainda em 1942 com a chamada Reforma Capanema, que extinguiu os cursos complementares nos quais a sociologia estava alocada (Oliveira, 2013). Sem embargo, não se pode negar que a disciplina permaneceu ausente dos currículos escolares, ainda que categorias, teorias e autores da sociologia tenham continuado a circular na realidade escolar de forma residual por meio de outras disciplinas escolares, tais como os chamados "estudos sociais". 
fechamento de Faculdades de Ciências Sociais (FERNANDEZ; OLIVEIRA, 2017). Este cenário complexo e contrastante serve de pano de fundo para compreendermos as singularidades que envolvem o ensino desta ciência nos dois países, pois estes distintos percursos possuem implicaçôes nas formas de conceber e operacionalizar a prática do ensino da sociologia.

É pertinente, ainda, indicar que o ensino secundário uruguaio possui orientaçóes em distintas áreas, o que se pretende implementar no Brasil por meio da chamada "Reforma do Ensino Médio ", de tal modo que a análise do caso uruguaio, considerando suas devidas particularidades, pode nos trazer indicativos para uma melhor compreensão da sociologia como disciplina escolar nesse cenário de mudanças.

Para uma melhor compreensão do leitor, organizarei meu artigo em mais três partes: a) breve apresentação das diferenças entre os sistemas educativos do Uruguai e do Brasil com relação ao Ensino Médio e à formação de professores; b) análise do ensino de sociologia no Uruguai a partir do ponto de vista dos professores; c) consideraçóes finais.

\section{O Ensino Médio e a Formação de Professores de Sociologia no Brasil e no Uruguai}

Ainda que o Ensino Médio brasileiro apresente certa heterogeneidade interna, marcada pela existência de algumas modalidades diferenciadas, como a educação de jovens e adultos, o Ensino Médio integrado à educação profissional e tecnológica etc., refiro-me neste texto ao "Ensino Médio regular", mantido principalmente pelas redes estaduais de ensino, que possuem autonomia com relação à organização que esta modalidade possui em cada unidade federativa. Também compreendo que, apesar da "Reforma do Ensino Médio" ter sido aprovada ainda em 2017, o cenário que analiso aqui se refere a um contexto no qual ela ainda não foi implementada de fato.

Para compreendermos de forma comparativa os sistemas educativos nos dois países temos que considerar as reformas educacionais vivenciadas na América Latina, principalmente a partir da década de 1990, uma vez que:

[...] observa-se que essas reformas se processam em sociedades com diferentes culturas políticas e associativas que seguramente intervêm, de alguma forma, na concretização das 
mudanças. Porém, a interação destas práticas culturais com as mudanças propostas não tem sido privilegiada nos estudos sobre a Reforma Educacional, nem naqueles que legitimam o seu conteúdo, nem tampouco na maioria daqueles que fazem uma avaliação crítica da mesma. (ROSAR; krawczyk, 2001, p. 40).

Uma das implicações que nos interessa de forma direta nesta análise é o fato de que em países como a Argentina e o Uruguai a produção de um sistema nacional de ensino se desenvolveu mais precocemente se comparado ao Brasil, tendo tido como pressuposto o processo de integração nacional. Isso implica afirmar que no Uruguai os currículos escolares e a formação de professores são unificados, diferentemente do que ocorre no Brasil, onde há maior heterogeneidade nestes dois níveis.

Outra observação importante é que o Ensino Médio regular brasileiro segue sendo unificado, com duração total de três anos e contando com diferentes disciplinas escolares, tendo sido a sociologia introduzida nacionalmente e oficialmente nesse currículo em 2008. No caso uruguaio, o Ensino Médio tem duração de seis anos, sendo três de formação geral, que é obrigatório, e outros três que são considerados preparatórios para o ingresso no ensino superior. $\mathrm{O}$ segundo ciclo de três anos do Ensino Médio uruguaio forma o que é denominado de Bachirellato, formado por um primeiro ano comum aos distintos percursos e dois anos de formação específica a partir das seguintes áreas de especialização: humanística, científica, biológica ou arte e expressão.

Ao passo em que no Brasil o ensino de sociologia ocorre em todas as séries do Ensino Médio, no Uruguai ele ocorre exclusivamente no quarto ano do Ensino Médio na área de especialização "humanísticas", contanto com quatro aulas semanais e um currículo unificado. É importante indicar que no Brasil a discussão sobre a possibilidade de um currículo unificado nacionalmente é antiga, e vem ganhando mais fôlego com a Base Nacional Comum Curricular (BNCC), ainda que se possa observar alguns retrocessos nessa discussão, considerando as diversas versóes da base já apresentadas ${ }^{4}$.

4 Há diferenças substantivas não apenas em termos de conteúdo apresentado nas distintas versões da base, como também de metodologia adotada em sua elaboração, pois, se como bem indicam Silva. Alves Neto e Vicente (2010, 2015), as versões de 2014 e 2015 são fruto de um emaranhado de sentidos gestados em 
No que tange à formação de professores, o modelo uruguaio também é unificado, possuindo um único desenho curricular para cada curso de formação docente, cujo ensino ocorre não nas universidades, mas sim em institutos específicos de formação de professores. Originalmente os cursos de formação de professores de sociologia se davam de forma unificada com a formação de professores em direito; porém, estas carreiras se autonomizaram em período recente (FERNANDEZ; OLIVEIRA, 2017).

Atualmente encontra-se em curso uma nova reforma no curso de formação de professores de sociologia no Uruguai, a partir da qual a formação será em sociologia e estudos de cidadania, o que reflete as próprias disputas no campo educacional local, uma vez que atualmente os licenciados em direito podem ensinar educação cidadá, mas os de sociologia não. Observa-se com isso que a formação de professores reflete as disputas epistemológicas no campo escolar, como também as disputas em termos de inserção profissional dos agentes que mobilizam este campo.

O curso de formação de sociologia está organizado no Uruguai em quatro anos de formação, estando as disciplinas assim distribuídas por ano: $\left.1^{\circ}\right)$ Teoria Social I, Mudanças e Permanências nas Sociedades Atuais, Sociologia do Espaço e do Tempo, Introdução à Didática; 20) Teoria Social II, Processos Econômicos Contemporâneos, Sociologia do Trabalho e do Ócio, Didática + Prática Docente; 30) Teoria Social III, Política, Estado e Cidadania, Identidade Cultural e Comunicação, Direitos Humanos, Didática II + Prática Docente; 40) Sociologia do Uruguai e a Religião; Teoria dos Métodos Sociológicos, Família Gênero e Relaçôes Amorosas, Didática III + Prática Docente.

No caso brasileiro há regulamentaçôes com relação aos cursos de formação de professores, sendo a resolução mais recente a CNE/CP no 2, de $1^{\circ}$ de julho de 2015. Na referida resolução é indicado que os cursos de formação de professores devam ter uma carga horária mínima de 3.200 horas, das quais 2.200 são referentes às atividades formativas, 400 de prática como componente curricular, 400 de estágio supervisionado, 200 de 
atividades teórico-práticas de aprofundamento em áreas de interesse dos estudantes. Todavia, a organização curricular é de responsabilidade das instituiçôes de ensino, que possuem autonomia no que tange à organização e estruturação do currículo dos cursos.

No Brasil temos mantido uma tradição de formação interdisciplinar para a formação de professores de sociologia, que articula esta ciência com a antropologia e a ciência política, modelo este consolidado principalmente a partir da segunda metade do século XX. Assim, apesar de inexistir um currículo definido nacionalmente para os diversos cursos de formação de professores de sociologia, predominantemente denominados de licenciaturas em Ciências Sociais ${ }^{5}$, há certa tradição que se replica em termos curriculares, o que inclui os conteúdos lecionados. Márcio de Oliveira (2015), ao analisar o ensino de teoria sociológica nos cursos de Ciências Sociais brasileiros, indica a replicação do que se é lecionado principalmente no que tange aos autores clássicos, havendo maior dispersão no ensino das teorias contemporâneas, o que nos dá algumas pistas sobre a complexidade e heterogeneidade que predomina nos cursos de formação de professores de sociologia no Brasil.

As questóes aqui elencadas sucintamente, acerca das diferenças com relação à estruturação do Ensino Médio e dos cursos de formação de professores nos dois países, nos possibilitam compreender melhor as diferentes posiçóes assumidas por docentes nestes diferentes contextos nacionais. Partamos, assim, para a análise de como o ensino de sociologia é pensado pelos docentes no Brasil e no Uruguai.

\section{As trajetórias dos professores de sociologia e no Uruguai}

O material empírico aqui analisado originou-se de entrevistas semiestruturadas realizadas na cidade de Montevidéu (Uruguai), entre o final do ano de 2017 e início de 2018. Foram selecionados cinco entrevistados uruguaios, compondo uma amostra aleatória não probabilística. Como o plano de fundo teórico que orienta a análise dos dados baseia-se nas teorias disposicionalistas (BOURDIEU, 1996, 2009; LAHIRE, 2015), é

5 Ante a recente expansão de tais cursos no Brasil, têm emergido também outros modelos formativos, os quais incluem licenciaturas em sociologia, em ciências humanas com habilitação em sociologia etc.; porém, ainda é majoritariamente predominante a denominação "ciências sociais" para se referir a tais cursos (OLIVEIRA, 2015). 
imprescindível um olhar mais cuidadoso para as trajetórias, para que assim possamos melhor compreender as práticas.

Neste momento será realizada uma aproximação inicial com as trajetórias de tais docentes a partir de suas falas, enfatizando-se, sobretudo, o ingresso na carreira docente e a prática profissional desenvolvida. Ressalta-se que o principal ponto de clivagem encontrado no grupo investigado refere-se à formação recebida, considerando-se uma primeira geração que realiza uma dupla formação em sociologia e em direito e uma segunda que passa a realizar uma formaçáo exclusiva em sociologia, havendo um aparente consenso de que a formação mais especializada atenderia melhor as demandas profissionais no Ensino Médio.

Apesar de compreender que o habitus envolve uma dimensão muito ampla em termos de trajetórias, busco focar nesse momento das disposiçôes sociais incorporadas dos professores com relação a seus deslocamentos sociais e, sobretudo, profissionais, buscando captar com isso o processo de "tornar-se" professor. Para um melhor esclarecimento acerca da forma como compreendo esta categoria, parto da seguinte definiçáo delimitada por Bourdieu (2009, p. 87):

[...] sistemas de disposições duráveis e transponíveis, estruturas estruturadas predispostas a funcionar como estruturas estruturantes, ou seja, como princípios geradores e organizadores de práticas e de representações que podem ser objetivamente adaptadas ao seu objetivo sem supor a intenção consciente de fins e o domínio expresso das operações necessárias para alcançá-los, objetivamente "reguladas" e "regulares" sem em nada ser o produto da obediência a algumas regras e, sendo tudo isso, coletivamente orquestradas sem ser produto da ação organizadora de um maestro.

Parto desta categoria, portanto, para compreender as trajetórias profissionais dos docentes nos dois países, considerando continuamente que as práticas se inscrevem não apenas nas disposiçôes sociais incorporadas, como também nas condições objetivas postas. Então, ao reconhecer que os cenários para o ensino de sociologia em ambos os países são distintos, compreendo que suas práticas inevitavelmente também são, ainda que possa haver pontos de convergência em ambas as realidades.

O exame das escolhas realizadas no âmbito da opção pela profissão docente nos leva a uma análise sociológica que se incide não apenas sobre 
as trajetórias acadêmicas dos agentes aqui investigados, como também por suas trajetórias sociais. Nesse sentido, toda trajetória é ao mesmo tempo individual e coletiva, de modo que ainda que as tomadas de posição dos agentes não possam ser reduzidas a variaçóes do habitus de classe, deve-se considerar o peso deste sobre as escolhas realizadas ${ }^{6}$.

No grupo de professores entrevistados a maior diferença formativa encontra-se em termos geracionais, uma vez que dois deles foram graduados no sistema que possibilitava a dupla formação, de professores de sociologia e de direito ${ }^{7}$, ao passo que três deles receberam uma formação exclusivamente sociológica. Todos eles receberam sua formação no Instituto de Professores Artigas (IPA), instituição de referência no âmbito da formação de professores no Uruguai, vinculado à Administração Nacional de Educação Pública. Entre aqueles que ingressaram na licenciatura quando havia uma dupla formação em direito e em sociologia é recorrente que o direito tenha sido o principal atrativo para o curso, o que se explica em parte pela sua presença mais incisiva no currículo do Ensino Médio no Uruguai.

Eu ingressei no Instituto de Professores Artigas no ano de 1990; em 1993, eu egressei. A opção que nos davam era educação cívica, direito e sociologia, era uma licenciatura que implicava como havendo duas epistemologias: a sociológica e o direito. Entretanto, o direito tinha uma formação, um peso muito maior. A opção pela sociologia veio depois. Eu ingressei na licenciatura pela opção jurídica. Depois, quando fiz minhas práticas, as fiz em sociologia. E, depois, fui aperfeiçoando por esse lado e abandonei o jurídico. (Entrevistada I).

Para mim o encontro com a sociologia foi muito casual, porque eu, na realidade, quando finalizei essa licenciatura, eu consegui grupos específicos de sociologia no quinto humanistico, no curso de sociologia. Comecei a dar aulas de sociologia. E me interessou. E comecei a me formar deste lugar, mas numa perspectiva muito autodidática e muito em relação à Faculdade. Neste momento, eu tinha muitos amigos que estavam fazendo o bacharelado em sociologia. Então, eu me nutria muito do que eles estavam fazendo, mas na realidade

6 Nesta pesquisa não nos centramos na questão da classe social, de tal modo que essa categoria não será operacionalizada de modo central na análise dos dados obtidos.

7 Apesar da temporalidade distinta é interessante perceber que o ensino de sociologia no Brasil origina-se fortemente atrelado ao direito, seja considerando o fato de que os primeiros catedráticos e autores de manuais eram em sua maioria bacharéis em direito (ENGERROFF; CICALES, 2016), seja pelo fato de que as primeiras cátedras criadas ainda no final do século XIX eram cátedras de direito, moral e sociologia (Oliveira, 2013). Isso pode apontar para um modelo comum em termos de gênese da sociologia latino-americana escolar; porém, necessitaríamos de uma pesquisa mais aprofundada para tanto. 
eu [...] digamos [...] não tenho uma formação acadêmica formal em sociologia. Minha formação tem a ver com meu próprio trajeto, com meu próprio interesse [...]. Eu não tenho formação direta na licenciatura em sociologia e tampouco tenho formação na Universidade, ou seja, tudo isso veio depois.

Mas como você escolheu a licenciatura em direito/sociologia?

Bem, foi um pouco por descarte, havia várias licenciaturas, queria fazer a de história, mas não pude fazer e entrei no de direito. Me interessa os dois. Me interessava mais a de história; mas, eu vinha do interior e não tinha pontos para ingressar no de história, e ingressei no de direito. (Entrevistado 2).

Eu escolhi ser professora de sociologia para ter uma fonte a mais de trabalho, para conseguir mais trabalho. Eu trabalhava dando aulas particulares, e tinha como predisposição para isso [...]. Eu era boa fazendo isso, mas tinha que me profissionalizar e trabalhava de tudo, de vendedora [...] porque de socióloga não me servia, tinha apenas contratos de seis meses [...]. Fazia pesquisas, mas era um trabalho muito precário. Eu fiz o bacharelado, dois anos de mestrado, procurei trabalho, mas bem [...] morreria de fome. Não era suficiente para viver só, me manter [...]. Eu gostei do IPA, me entusiasmei. Eu consegui revalidar 50\% das matérias [...]. Mas basicamente porque me dei conta que era uma fonte de trabalho e porque eu era boa dando aulas. (Entrevistada 3).

Eu na realidade tenho uma formação dupla, quando saí do Ensino Médio vim à Faculdade de Ciências Sociais, que era muito diferente do que é agora, isso era em 2005. Minha primeira descoberta com a sociologia foi no quinto ano, no Ensino Médio. Aqui a sociologia está no quinto ano se escolhes a orientação humanística, nas demais orientações não aparece [...] quando eu terminei, que conheci a sociologia, eu me apaixonei pela matéria e quis explorar. E vim para as ciências sociais, e fiz três anos de sociologia. A formação são quatro, o bacharelado. Daí me dei conta que a pesquisa não era o que me agradava mais, não era o que mais me apaixonava. Neste momento no IPA ainda não estava separada a licenciatura de direito, que antes recebia o título de professor de direito, de educação cívica e de sociologia. Essa formação não tinha sociologia, era uma sociologia I isolada. Enem se pensava uma didática e uma prática de sociologia, ou seja, era uma licenciatura de direito. E, como eu não queria fazer direito, eu vim para a Faculdade de Ciências Sociais [...]. Quando abriu em 2008 a licenciatura específica de sociologia, eu fui para lá. Bem, então, sou egressa do IPA, mas eu transitei por aqui também. (Entrevistada 4).

A partir dessas falas, é possível observar como que as mudanças ocorridas no nível da formação inicial também produziram diferentes trajetórias pelo curso de formação de professores em sociologia, uma vez que as duas últimas entrevistas - que já ingressaram no plano currículo após 2008 quando passa a haver a formação específica em sociologia - apontam para uma trajetória mais claramente direcionada para a sociologia. Em todo o 
caso, também chama a atenção o papel que a presença da sociologia no currículo escolar passa a ter no caso uruguaio, aparecendo como um fator capaz de atrair jovens para a carreira de sociologia, o que não apareceu no caso brasileiro (BODART; TAVARES, 2018), possivelmente devido à recente reintrodução da sociologia no currículo escolar.

Em entrevistas realizadas com professores brasileiros encontramos que as "disciplinas pedagógicas" da licenciatura parecem ganhar pouco destaque, de modo que o interesse pela docência acaba sendo "despertado" principalmente a partir de situaçóes objetivas que se colocam após a conclusão do curso. E isso contrasta com o caso uruguaio, o que se explica, em parte, pelo fato de a formação de professores ocorrer em um espaço específico para tanto. Como observado, em todo o caso para alguns docentes no Uruguai a prática é um espaço relevante para se "despertar" a vocação específica pelo ensino de sociologia, e isso inclui também a prática profissional após a conclusão do curso. Sendo assim, é importante considerar alguns aspectos para melhor compreender a passagem de um estado inicial, no qual não há um interesse claro na docência, para outro, no qual ocorre o ingresso na profissão:

Os acontecimentos biográficos definem-se antes como alocações e como deslocamentos no espaço social, isto é, mais precisamente, nos diferentes estados sucessivos da estrutura da distribuição dos diferentes tipos de capital que estão em jogo no campo considerado. É evidente que o sentido dos movimentos que levam de uma posição a outra (de um editor a outro, de uma revista a outra, de um bispo a outro etc.) define-se na relação objetiva entre o sentido dessas posições no momento considerado, no interior de um espaço orientado. Isto é, não podemos compreender uma trajetória (ou seja, o envelhecimento social que, ainda que inevitavelmente o acompanhe, é independente do envelhecimento biológico), a menos que tenhamos previamente construído os estados sucessivos do campo no qual ela se desenrolou; logo, o conjunto de relações objetivas que vinculam o agente considerado - pelo menos em certo número de estados pertinentes do campo - ao conjunto dos outros agentes envolvidos no mesmo campo e que se defrontam no mesmo espaço de possíveis. (BOURDIEU, 1996, p. 81-82).

Para o nosso caso isso, significa afirmar que há uma necessidade de compreendermos as dinâmicas próprias do campo da educação, que remete, dentre outras questôes, às condiçôes estruturais às quais os professores da educação básica são submetidos, despertando um parco interesse na carreira mesmo entre aqueles que cursam uma licenciatura. Mas, por outro 
lado, o egresso do curso de ciências sociais/sociologia por vezes encontra na atuação na educação básica um campo de atuação profissional mais amplo, que oferece condiçóes de ingresso mais claras que o campo da pesquisa, o que parece ser uma realidade relativamente comum em ambos os países. Apesar dos professores uruguaios fazerem referências às poucas aulas que eles podem assumir, já que a sociologia está localizada apenas no quinto ano do curso humanístico, eles reconhecem que essa é a orientação mais recorrente nas escolas uruguaias, nas quais há maior procura por parte dos alunos.

A inexistência de uma dupla formação em direito e em sociologia para os professores uruguaios implicou em ganhos em termos formativos; porém, houve uma perda com relação aos espaços de atuação profissional, o que é avaliado negativamente, especialmente pelo fato de que há uma compreensão de que eles também deveriam estar habilitados para o ensino de educação cidadã, que está presente inclusive no Ensino Fundamental. Em outros termos, a dupla formação implicava na existência de uma licenciatura centrada no direito, e que apenas secundariamente oferecia uma formação teórica e metodológica no campo da sociologia; porém, ao separarem as duas formaçóes, o ensino de educação cidadã passou a ser uma tarefa que apenas poderia ser exercida exclusivamente pelos docentes com formação em direito, excluindo os profissionais egressos da licenciatura em sociologia.

Torna-se evidente, desse modo, que as disposiçóes sociais dos professores de sociologia são estruturadas a partir de suas experiências anteriores em nível de formação acadêmica, a socialização ocorrida em outros espaços, e também a partir das condiçôes objetivamente postas, algo semelhante ao que encontramos em pesquisa com professores brasileiros (OLIVEIRA, 2019). A formação inicial aparece, portanto, como um dos elementos que compóem a prática desses agentes; entretanto, é combinada com outras experiências sociais vivenciadas ao longo de uma trajetória.

A relação que tais docentes estabelecem com esta área de conhecimento deve ser compreendida; portanto, a partir dos próprios dilemas que se colocam na realidade dos professores da educação básica. Observa-se, com isso, que a construção da identidade docente no caso brasileiro vai 
se constituindo principalmente a partir das demandas que se colocam na ordem do campo prático, ao passo que no caso uruguaio essa identidade aparentemente se constrói antes mesmo da escolha pelo curso, o que pode ser explicado pelo fato de a disciplina já se encontrar mais consolidada no currículo escolar, além da existência de espaços de formação docente específicos. Ainda que recorrentemente torna-se professor de sociologia não tenha sido a primeira opção para estes docentes, a docência acaba por ser uma possibilidade objetiva de inserçáo no mercado de trabalho, o que ocorre por vezes.

\section{A prática do ensino de sociologia}

Como já indicado anteriormente, no Uruguai a formação docente se dava de forma interdisciplinar juntamente com o direito e a educaçáo cívica $^{8}$, é apenas a partir de 2008 que surge o que é denominado de novo "plano curricular", que possibilita uma formação específica em ensino de sociologia, ainda que a formação sociológica no bacharelado fosse anterior a esse processo. Isso implica considerar que houve continuamente no Uruguai espaços voltados para a reflexão sociológica, com alguns períodos de interrupção de seu funcionamento, mas que não implicaram a existência de espaços específicos para a reflexão acerca do ensino da sociologia, em que pese sua presença no currículo escolar desde a década de 1960.

$\mathrm{O}$ que quero demonstrar com isso é que o ensino de sociologia no Uruguai tensiona com dilemas distintos daqueles que encontramos no caso do ensino de sociologia no Brasil, que se vinculam, por um lado, às formas como a sociologia é inserida e como se mantém no currículo escolar; por outro, às especificidades que envolvem os modelos de formação de professores adotados em ambos os países.

Se o debate, em termos de políticas públicas no Brasil, tem sido apontado para um desenho de cada vez maior produção de uma identidade própria dos cursos de formação de professores, como bem demonstram os

8 É interessante notar que algo semelhante se passou no Brasil, ainda que em outros termos, na medida em que por muitos o curso de ciências sociais habilitava seus para lecionarem Organização Social e Política do Brasil (OSPB), disciplina criada em 1963 e que constou no currículo escolar até o início da década de 1990, mas que incorporou distintos sentidos ao longo dos anos, especialmente durante o período da ditadura militar. 
documentos oficiais (OLIVEIRA, A. , 2015); porém, mantendo-se uma formação de certo modo conjunta com o bacharelado, no Uruguai o modelo de espaço de formaçáo docente parece extremar o que tem sido apontado pelo debate no Brasil, o que tem sido também passível de críticas.

A diferencia de lo que ocurre en el mundo desarrollado, donde la formación docente ocurre en centros productores de conocimiento - es decir, universidades -, en Uruguay la misma se produce dentro del llamado "Sistema ANEP", en centros normalistas, desvinculados de la generación de conocimiento disciplinar y pedagógico, lo que lleva a que en "la mayoría de los casos, el profesor no suele dominar en el nivel primario las claves que explican la evolución del saber y de la cultura". (Gimeno Sacristán, 1989:1/4). Además, por sus características organizacionales y reglamentarias, la FD constituye parte fundamental de un circuito cerrado que perjudica, en muchos casos, la promoción y el ingreso de los más capacitados para la docencia: la obtención del título otorga derecho a una plaza laboral dentro del mismo sistema que lo expide, pero sólo se promueve por antigüedad simple.

Esta situación resulta de una suerte de "paradoja de consecuencias" (Weber, 1944), por la cual cada esfuerzo de institucionalización de la formación docente para la educación secundaria deterioró la preparación de los egresados. Tanto en 1949 como en 1996 se fundaron institutos de FD (IFD) con interés en lo educativo, pero en total aislamiento, e incluso opuestos, respecto de los centros de generación de conocimiento nuevo en las distintas disciplinas, particularmente de la Universidad. (MARRERO, 2010, p. 112-113).

Esta maior ou menor especificidade em termos de formação docente, assim como a maior ou menor consolidação da sociologia no currículo escolar, têm implicaçóes diretas sobre as práticas, pois estes dois fatores remetem tanto às disposiçóes sociais incorporadas (habitus) quanto às condiçóes objetivas nas quais a prática de produz. Um exemplo significativo dessas diferenças em termos de condiçôes objetivas é a existência no Brasil do Programa Nacional do livro Didático (PNLD) ${ }^{9}$, que constitui uma política de Estado, havendo a distribuiçãao gratuita de livros, sendo sempre elogiados os livros didáticos de sociologia pelos professores brasileiros com os quais realizei entrevistas, ao passo que os professores uruguaios se inscrevem mais claramente em uma tradição "antimanualística", indicando inclusive a parca produção de manuais de sociologia voltados para o ensino

9 O PNLD é um programa de Estado que inclui a avaliação, aquisição e distribuição de livros didáticos em escolas públicas de todo o país, tendo sido ampliado gradativamente ao longo dos anos. No caso da sociologia, esta disciplina está presente neste programa desde 2012, tendo já participado de três editais, nos quais foram aprouados dois, seis e cinco liuros, respectivamente. 
de sociologia no Ensino Médio. Como indica a Entrevistada U1, o uso de manuais por vezes se encontra mais restrito ao processo de organização e produção dos planos de ensino, e menos ao uso em sala de aula.

Também é interessante perceber que, aparentemente, o uso dos manuais didáticos no Uruguai parece perder espaço, ou ao menos certo tipo de seu uso. Como indica o Entrevistado U2:

Também se reproduzia muito [...]. Era muito comum reproduzir manuais [...]. Manuais de sociologia que se reproduzia, na realidade se repetia tal como estava. Os primeiros manuais que chegaram aqui nos anos 1990 não tinham perspectiva sociológica tampouco. A perspectiva não era uma coisa que aparecia. [...] 0 boom dos manuais aparece com o manual de Giddens, é um de maior recepção, entre os melhores no momento.

Notadamente o uso dos livros didáticos constitui uma parte do que os professores fazem em sala de aula, seja no caso brasileiro, seja no caso uruguaio, havendo um destaque contínuo à necessidade de se tentar práticas inovadoras no ensino. Isso não significa que se desreconheça a relevância do livro didático em sala de aula, especialmente em contextos nos quais os professores não são especialistas em suas áreas de atuação; todavia, enfatiza-se que no contexto uruguaio foi encontrada uma clara resistência ao uso exaustivo dos livros didáticos, o que é reforçado pela ausência de uma Política de Estado nesta direção. A combinação de diferentes recursos didáticos também aparece entre os professores uruguaios, ainda que nesse caso o livro perca mais espaço. Como nos indica a Entrevistada 4:

Eu trabalho muito, com uma coisa que é muito efetiva, que são os audiovisuais. Isso você vai adquirindo na prática. Eu trabalho basicamente com audiovisuais, que os mantêm bastante atentos. Seja filmes ou documentários, ou publicidade, depende do que vamos analisar. Depois trabalho muito com "texto fonte" [...] Em um momento eu estava muito frustrada com isso, porque o nível de leitura não é o esperado[...]. Eu creio que isso, em comparação de quando eu fiz o bachirellato, que não faz tanto, há baixado muito a disposição a leitura [...]. Faz com que tenhas que produzir estratégias de aula para que isso ocorra [...]. Um Marx, que é praticamente inabarcável. Eu trabalho às vezes com um texto fonte, para eles terem uma ideia de como ele fala, como se expressa, mas também trabalho com fichas, com textos curtos [...] em um momento me dei conta que isso estava demasiadamente digerido, filtrado por mim, mas senti como se eu estivesse os tratando como bebês. Então, comecei a mesclar. Uns temas que eram mais dificeis, eu trazia fichas. Por outro lado, o texto fonte, porque eles também iam necessitar. Querendo ou não, esse é em muitos casos o caminho para a universidade. 
Esta fala nos dá pistas para compreendermos que o fato do Ensino Médio também apresentar estruturações distintas em ambos os países, e isso possui implicaçóes sobre as práticas, uma vez que o Ensino Médio uruguaio possui diferentes orientaçóes voltadas para a formação universitária. Neste cenário, a sociologia encontra-se apenas nesse segundo ciclo, de modo que o uso de determinados recursos didáticos passa a ser pautado também, por isso, pela finalidade que é pensado o segundo ciclo do Ensino Médio, ganhando espaço o acesso direto a textos de autores clássicos, o que seria considerado algo relevante para a carreira universitária a ser vivenciada pelo egresso do bachillerato.

Em ambos os casos, ainda que em situaçóes substancialmente distintas, os professores indicam a falta de reconhecimento da disciplina, e parco espaço que ela possuí. No caso uruguaio o principal problema relaciona-se à presença da sociologia exclusivamente no quinto ano da orientaçáo de humanidades, ao passo que no Brasil isso remete ao número reduzido de aulas, além da ameaça recente de perda de espaço devido à chamada "Reforma do Ensino Médio" (OLIVEIRA; BINSFELD; TRINDADE, 2018). Apesar de ser indicado que a orientação em humanidades é a mais recorrente nas escolas uruguaias, havendo a maior procura entre os jovens, também é indicado que faltam aulas para os professores, ao passo que no Brasil um dos maiores problemas é o fato de que os docentes recorrentemente assumem mais de uma disciplina. Neste sentido, é razoável indicar que "Parece que os professores sentem-se encurralados em um mundo de não reconhecimento do qual apenas eles mesmos (como, outrora, o barão Münchhausen) podem se safar, 'puxando-se pelos próprios cabelos para sair do pântano” (LEITHAUSER; WEBER, 2010, p. 93). Há um amplo reconhecimento das condiçóes adversas encontradas na escola pública, assim como dos limites da formação pedagógica recebida. E tais elementos foram apontados por todos os entrevistados.

Analisando tais questóes a partir das teorias disposicionalistas, percebe-se que as práticas são condicionadas, de certo modo, a partir das disposiçóes sociais incorporadas. Desse modo, as experiências sociais anteriormente vivenciadas são sedimentadas nos agentes, que expressam esta relação a partir de suas práticas no mundo. A maior ou menor aproximação com o livro didático, a combinação de diversos recursos didáticos, a 
percepção ou não da existência de uma didática própria da sociologia são questôes que emergem neste cenário vinculadas ao habitus dos agentes.

Chamo atenção aqui para o papel exercido não apenas na socialização primária nesse processo, como também pela socialização secundária, vivenciada tanto nos cursos de formação de professores quanto na prática profissional (LAHIRE, 2015). Um ponto que parece mais fortemente entre os professores uruguaios que entre os brasileiros é a relevância que é dada ao papel que os pares possuem em um processo de debate contínuo sobre a prática, sobre os fundamentos didáticos e epistemológicos do ensino da sociologia.

A relação com o livro didático parece-me especialmente emblemática nas diferenças presentes em termos de disposiçôes sociais, pois, os professores formados em ciências sociais (Brasil) e sociologia (Uruguai) tendem a valorizar seu distanciamento com relação ao livro, apontando a utilizando de outros recursos e leituras. Levanto a hipótese que a maior ou menor aproximação com o livro didático de sociologia acaba se tornando um elemento de distinçáo social, nos termos postos por Bourdieu (2007), na medida em que uma maior distância em relação a este material indicaria um maior capital acadêmico no campo específico da sociologia, a existência de outras leituras mais aprofundadas e específicas que possibilitaria uma maior autonomia com relação ao livro didático, ao passo que este mesmo material representaria, para os professores de sociologia formados em outras áreas, um elemento importante de legitimação para os conteúdos de suas aulas.

Assim, a prática pedagógica dos professores de sociologia somente pode ser compreendida à luz da análise das trajetórias sociais dos agentes, inserindo-as dentro de um quadro mais amplo com relação aos cursos de formação de professores, à estruturação do sistema educativo e o lugar da sociologia no currículo escolar. Os diferentes percursos que são traçados implicam em aproximaçóes distintas com a sociologia como disciplina escolar, assim como com os elementos que compóem esta realidade, dentre os quais se destaca o livro didático. Certamente a formação inicial é um dos elementos decisivos neste processo; porém, não é o único, considerando-se em especial o fato de que outros processos de socialização também possuem peso sobre as práticas dos agentes (LAHIRE, 2015). 


\section{Considerações finais}

Ainda que esta seja uma aproximação inicial, com dados incipientes sobre a atuação de professores de sociologia no Uruguai com alguns elementos comparativos com o caso brasileiro, compreendo que a análise comparativa nos possibilita problematizar algumas questôes que não estariam postas ao observarmos apenas os casos nacionais isolados.

Em ambos os países os professores apontam para a boa recepção dos jovens do ensino de sociologia, e da relevância que percebem nessa disciplina para a formação dos educandos, especialmente dentro do cenário tão recorrente nas sociedades latino-americanas, marcadas por uma profunda desigualdade econômica e social. Ao mesmo tempo, também possuem como ponto em comum os desafios didáticos que se colocam no processo de transmutação dos conhecimentos sociológicos adquiridos no ensino superior em conhecimentos para a educação básica; nesse ponto, as diferenças começam a ficar mais visíveis, na medida em que os professores uruguaios continuamente referem-se à relevância que a formaçáo didática teve em seus cursos superiores, destacando o papel dos professores "tutores" nesse processo, como que em uma troca que possibilitaria o desenvolvimento de uma didática do ensino de sociologia como um campo próprio de reflexão. Isso não é vivenciado de forma acrítica, todavia. Também se reconhecem as hierarquias acadêmicas e que a formação nos cursos de licenciatura em termos teóricos "não seria boa" (Entrevistada U3).

Embora não seja possível realizar grandes generalizaçóes a partir deste estudo, chamam-nos a atenção as possibilidades que são abertas a partir da comparação com outras experiências, especialmente no contexto dos países do Cone Sul. Mostra-se evidente que o modelo formativo docente adotado no Uruguai possui ganhos e perdas em relação ao que adotamos no Brasil, já que, se por um lado reforça a formaçáo da identidade docente, por outro, separa ainda mais a formação de professor e a de pesquisa. Ademais, a presença da sociologia apenas em algumas orientações do Ensino Médio uruguaio pode nos trazer pistas importantes sobre as possibilidades objetivas que se colocam para o ensino de sociologia no Brasil ante a chamada Reforma do Ensino Médio. 


\section{Referências}

BODART, C. das N.; CIGALES, M. P. Ensino de sociologia no Brasil (1993-2015): um estado da arte na pós-graduação. Revista de Ciências Sociais, v. 48, n. 2, p. 256-281, 2017.

BODART, C.; TAVARES, C. dos S. Programas de fomento a expansão do ensino superior e oferta de cursos de ciências sociais no Brasil (1999-2017). Cadernos da Associaçáo Brasileira de Ensino de Ciências Sociais, v. 2, n. 1, p. 7-29, 2018.

BOURDIEU, P. Razóes práticas. Campinas: Papirus, 1996.

BOURDIEU, P. A Distinçáo: crítica social do julgamento. São Paulo: Edusp; Porto Alegre: Zouk, 2007.

BOURDIEU, P. O senso prático. Petrópolis: Vozes, 2009.

CAREGNATO, C. E.; CORDEIRO, V. C. Campo científico-acadêmico e a disciplina sociologia na escola. Educaçáo \& realidade, v. 39, n. 1, p. 39-57, 2014.

ENGERROFF, A. M; CIGALES, M. P. A constituição da sociologia no Brasil e o direito: a formação dos intelectuais, Revista Urutágua, n. 35, p. 80-101, 2016.

FERNANDEZ, D; OLIVEIRA, A. As outras histórias da Sociologia escolar na América Latina: um olhar desde o Uruguai com Daniela Fernandez. Cadernos da Associaçáo Brasileira de Ensino de Ciências Sociais, v. 1, n. 2, p. 134-141, 2017.

HANDFAS, A. As pesquisas sobre o ensino de sociologia na educaçáo básica. In: SILVA, I.; GONÇALVES, D. N. Sociologia na educação básica. São Paulo: Annablume, 2017. p. 367-385.

LAHIRE, B. A fabricação social dos indivíduos: quadros, modalidades, tempos e efeitos de socialização. Educ. Pesqui, v. 41, n. spe, p. 1393-1404, 2015.

LEITHAUSER, T.; WEBER, S. Ética, Moral e Política na Visão de Professores Brasileiros e Alemães. Estudos de Sociologia, v. 16, n. 1, p. 87-108, 2010.

LIEDKE FILHO, E. D. A sociologia no Brasil: história, teorias e desafios. Sociologias, v. 7, n. 14, p. 376-436, 2005.

MAÇAIRA, J. P. O ensino de sociologia e ciências sociais no Brasil e na França: recontextualização pedagógica nos livros didáticos. Orientador: Philippe Vitale. 2017. 342 f. Tese (Doutorado em Sociologia e Antropologia) - Instituto de Filosofia e Ciências Sociais, Universidade do Rio de Janeiro: Rio de Janeiro, 2017.

MARRERO, A. Formación docente y producción de conocimiento en el sistema de educación superior uruguayo: una cuestión sin resolver. RAES - Revista Argentina de Educación Superior, v. 2, n. 2, p. 111-133, 2010.

MEUCCI, S. Sociologia na Educação Básica no Brasil: um balanço da experiência remota e recente. Revista Ciências Sociais Unisinos, v. 51, p. 251-260, 2015.

MORAES, A. C. 2011.Ensino de Sociologia: periodização e campanha pela obrigatoriedade. Cadernos Cedes, v. 31, n. 85, p. 359-382, 2011.

OLIVEIRA, A. Revisitando a história do ensino de Sociologia na Educação Básica. Acta Scientiarum Education, v. 35, n. 2, p. 179-189, 2013. 
OLIVEIRA, A. Ensino de Sociologia: novas temáticas e experiências internacionais. Educaçáo \& Realidade, v. 39, p. 11-16, 2014.

OLIVEIRA, A. Trajetórias e práticas pedagógicas entre professores de sociologia. Diálogo Educacional, v. 19, n. 60, p. 308-327, 2019.

OLIVEIRA, A. Cenários, Tendências e Desafios na Formação de Professores de Ciências Sociais no Brasil. Política \& Sociedade, v. 14, n. 31, p. 38-61, 2015.

OLIVEIRA, A.; BINSFELD, W; TRINDADE, T. A Reforma do Ensino Médio e suas Consequências: O que pensam os professores de sociologia?. Revista Espaço do Currículo, v. 11, n. 2, p. 249-259, 2018.

OLIVEIRA, M. O ensino da teoria sociológica em alguns cursos de Ciências Sociais de universidades públicas brasileiras. Política \& Sociedade, v. 14, n. 31, p. 87-113, 2015.

ROSAR, M. de F. F.; krawczyk, N. R. Diferenças da homogeneidade: elementos para o estudo da política educacional em alguns países da América Latina. Educaçáo \& Sociedade, v. 23, n. 75, p. 33-47, 2001.

SILVA, I.; NETO, H. F. A.; VICENTE, D. V. A proposta da Base Nacional Comum Curricular e o debate entre 1988 e 2015. Revista Ciências Sociais UNISINOS, v. 51, n. 3, p. 330-342, 2015.

SILVA, I.; ALVES NETO, H. F.; VICENTE, D. V. O Ensino das Ciências Sociais/Sociologia no Brasil: histórico e perspectivas. In: MORAES, A. C. de (Org.). Coleçáo Explorando o Ensino de Sociologia. Brasília: MEC, 2010. p. 23-31.

\section{The Teaching of Sociology in Uruguay: an analysis from the teacher's narratives}

\section{Abstract}

This work examines the teaching of sociology in Uruguay bringing some purchasing elements with Brazil, which will be done considering both the peculiarities in terms of educational systems in both countries, as well as, and especially, the evaluations carried out by sociology teachers. Methodologically the work is based on semi-structured interviews conducted in Montevideo, with emphasis on the trajectories of the agents and their incorporated social dispositions. It is observed that the Uruguayan teachers consolidate a teaching identity still in its initial formation, however, there is an evident generational cut among those who carried out the training before and after 2008. It was also found as a characteristic a strong "antimanualist" position of Uruguayan sociology teachers, reinforced by the tendency to combine different teaching methodologies in their practices.

Keywords: Teaching Sociology. Sociology Teachers. Sociology in Latin America. Sociology in Uruguay.

Recebido em: 17/10/2018

Aprovado em: 22/01/2019 